\section{El Bosco. La exposición del V Centenario}

Museo Nacional del Prado, Madrid 31 de mayo - 11 de septiembre de 2016 Comisaria: Pilar Silva Maroto

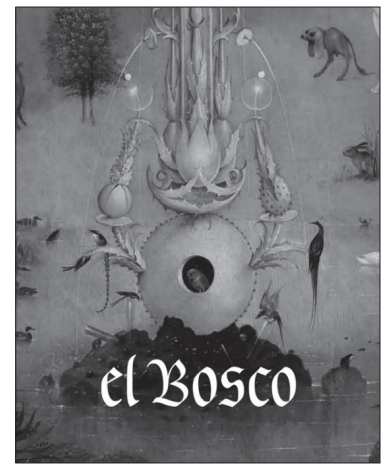

Ana Ávila

que siempre se muestra tan extraño pintando raros personajes y actitudes curiosas.

FELIPE de Guevara Comentarios de la pintura, c. 1560

1 516: muerte de El Bosco. Corresponde a 2016 el V Cente1 nario del fallecimiento de este pintor nacido en lo que actualmente es el sur de los Países Bajos. Es lógico pensar que España se sumara a este acontecimiento por cuanto Madrid - Museo del Prado, Patrimonio Nacional y Museo Lázaro Galdiano- conserva un número significativo de sus obras. La pinacoteca nacional cuenta con seis piezas suyas, ${ }^{1}$ siendo aceptadas por unanimidad como indiscutibles los trípticos de la Adoración de los Magos y El jardín de las delicias. De hecho, pocas obras en el Museo del Prado acaparan tanta atención por parte de los visitantes como El jardín de las delicias, sin duda, una de las referencias de sus fondos y con la que se asocia el museo entre los extranjeros.

La exposición en el Museo del Prado vino precedida por circunstancias que trascendieron a los medios de comunicación. En esta se puede contemplar una tabla con la representación de Cristo camino del Calvario (c. 1500), perteneciente a las colecciones reales y conservada en el Real Monasterio de San Lorenzo de El Escorial. Precisamente a Patrimonio Nacional pertenecen algunas obras de El Bosco que se conservan en el Prado: El jardín de las delicias y La mesa de los Pecados Capitales. El monasterio escurialense contaba con estas desde que Felipe II las hiciera llegar, la primera en la década de los noventa y la segunda en el envío realizado en 1574. Durante la Segunda República, en la década de los treinta, El jardín de las delicias ingresa en el Museo del Prado, y que por un decreto de 1943 la naturaleza jurídica de esta y de cuatro obras más de Patrimonio

1. La Adoración de los Magos (c. 1494), El jardín de las delicias (c. 1490-1500), La mesa de los Pecados Capitales (c. 1505-1510), Las tentaciones de san Antonio Abad (c. 1510-1515), La extracción de la piedra de la locura (1501-1505) y El carro de heno (c. 1512-1515), según cronologías defendidas por el catálogo de la exposición. El propio museo atribuye al taller de El Bosco otra tabla con Las tentaciones de san Antonio Abad (c. 1510-1515).
Nacional vendría a ser la de depósito indefinido. La realidad del Museo de las Colecciones Reales ha generado la posibilidad de disponer de los referidos cuadros. El revuelo causado ha originado un acuerdo entre ambas partes a fin de que no se pierda para la pinacoteca nacional la facultad de mostrar obras como las mencionadas de El Bosco, sin que Patrimonio Nacional pierda su titularidad. No en vano, el Museo del Prado ha puesto énfasis en que la exposición de El Bosco está organizada con la colaboración especial de este organismo público.

Otra cuestión que acarreó cierta desazón fue la labor emprendida por un grupo de investigadores bajo la denominación de Bosch Research and Conservation Project (BRCP). ${ }^{2}$ La Fundación que lleva su nombre dispuso de un comité científico — con miembros de museos y universidadesy de un equipo de investigadores en los ámbitos de la historia del arte y la técnica puesta al servicio del arte. Veintiocho museos e instituciones participaron en la investigación, entre estos, el Museo del Prado, el Museo Lázaro Galdiano, el Museu de Belles Arts de València y Patrimonio Nacional. El resultado de más de seis años de trabajo es un catálogo razonado en el que se estudia las obras pictóricas y los dibujos de El Bosco bajo distintos puntos de vista, siendo de gran valía los de tipo técnico. ${ }^{3}$ La organización de la producción del artista a partir de obras propias, piezas de taller y obras de seguidores ha trastocado algunas atribuciones, como la autoría de tres ejemplares del Museo del Prado, $L a$ extracción de la piedra de la locura, Las tentaciones de san Antonio Abad y La mesa de los Pecados Capitales, que el equipo adjudica a un seguidor. Por el contrario, obras que eran dudosas han sido reivindicadas como indiscutibles, tal es el caso del tríptico de El Juicio Final del Groeningemuseum de Brujas. Sin embargo, la opinión del Museo del Prado es diferente; esta institución se sintió dolida cuando, meses antes de que el BRCP diera a conocer los resultados de la investigación, uno de los responsables del grupo participó en un documental en el que cuestionaba que La mesa de los Pecados Capitales fuera un original. Es más, el Prado, como respuesta a la alteración de las condiciones contractuales, recapacitó sobre el préstamo de La extracción de la piedra de la locura y Las tentaciones de san Antonio Abad, piezas que no se pudieron ver en el Noordbrabants Museum de 's-Hertogenbosch con motivo de la exposición de El Bosco, a pesar de que figuran en su catálogo.

La exposición del Museo del Prado ha sido precedida por otras celebradas en los Países Bajos. Así, habría que remontarse a 2001 cuando en el Museum Boijmans Van Beuningen de Róterdam se celebró una monográfica del artista, museo de donde viene a Madrid la tabla que representa a San Cristóbal con el Niño Jesús a cuestas y el dibujo del Nido del búho. Entre octubre de 2015 y enero de 2016 se desarrolló la muestra De El Bosco a Brueghel. Descubriendo la vida cotidiana ${ }^{4}$ donde el tríptico de El carro de heno, del Museo

2. http://boschproject.org

3. Ilsink, M.; KoldeweiJ, J.; Spronk, R.; Hoogstede, L.; ErDManN, R.G.; Klein Gotink, R.; HanneKe, N.; Veldhuizen, D., Hieronymus Bosch. Painter and Draughtsman. Catalogue Raisonné. New Haven - Londres: Mercatorfonds - Yale University Press, 2016.

4. Con Friso Lammertse como uno de sus comisarios. 
del Prado, se alzaba como la pieza paradigmática. Jheronimus Bosch. Visiones de un genio es el título de la exposición celebrada en la localidad natal del artista, 's-Hertogenbosch, concretamente en el Noordbrabants Museum, entre febrero y mayo de 2016. ${ }^{5}$ Allí también se expuso el referido tríptico así como San Juan Bautista en meditación, del Museo Lázaro Galdiano, y entre las obras que no se ven en la exposición del Prado figuraba el tríptico de los Santos ermitaños, de las Gallerie dell'Accademia de Venecia; sin embargo, no se encontraba ninguna otra del Prado, ni la Coronación de espinas de la National Gallery de Londres, así como tampoco una de las estrellas de la exposición madrileña, el tríptico de Las tentaciones de san Antonio Abad del Museu Nacional de Arte Antiga de Lisboa, y, en cuanto a los dibujos, no se vio el espectacular Hombre-árbol de la Albertina de Viena. También es lógico considerar que El Escorial tenía que sumarse a la celebración de los quinientos años de la muerte de El Bosco por cuanto en su monasterio se congregaron diversas piezas suyas consideradas, por entonces, obras indiscutibles. Allí fueron destinadas por su coleccionista, Felipe II, en diversas entregas, y sobre las mismas especuló el jerónimo fray José de Sigüenza en su Fundación del monasterio de El Escorial (1602), quien calificó la obra del artista como una «sátira pintada de los pecados y desvaríos de los hombres», haciendo énfasis en la lectura moralizante que suele hacerse de ella. En esta exposición se puede ver la copia de extraordinaria calidad de El carro de heno (c. 1512-1515), que por primera vez se exhibe tras su reciente restauración, la cual perteneció a Diego de Guevara, chambelán en las cortes de Felipe el Hermoso y Carlos V, pieza que heredaría su hijo ilegítimo Felipe de Guevara, cuyos descendientes lo venderían al monarca español. Siendo la Coronación de espinas una obra de taller, es interesante contemplar la tapicería conocida como «Disparates de El Bosco o Caprichos de Brueghel», inspirada en la producción de El Bosco según cartones atribuidos a Pieter Brueghel el Viejo, tenida como una de las colgaduras más importantes que conserva las Colecciones Reales, tejida en Bruselas entre 1550-1560 con hilos de oro, plata y seda. ${ }^{6}$

En el ámbito del Museo del Prado, hay que tener en cuenta el precedente de la exposición El jardín de las delicias de El Bosco: copias, estudio técnico y restauración, celebrada en el Prado (2000), comisariada, como la actual, por Pilar Silva Maroto. ${ }^{7}$ En El Bosco. La exposición del V Centenario se presentan cincuenta y tres piezas gracias a los préstamos de diversos museos que afortunadamente conservan obras del artista o con él vinculadas. ${ }^{8}$ La contrapartida que

5. Comisariada por Matthijs Ilsink y Jos Koldeweij.

6. Su interés también estriba en que es una versión - ya el único conjunto existente - de la princeps, tejida para Francisco I de Francia, destruida durante la Revolución francesa.

7. Tras la restauración de El jardín de las delicias debida a María Teresa y Rocío Dávila.

8. Aparte del Museo del Prado, en España contamos con obras del Museo Lázaro Galdiano, del Museu de Belles Arts de València y de Patrimonio Nacional. De Holanda proceden piezas de 's-Hertogenbosch (Noordbrabants Museum), Ámsterdam (Rijkmuseum) y Róterdam (Museum Boijmans Van Beuningen), y de Bélgica, del Groeningemuseum de Brujas y del Museum voor Schone Kunsten de Gante. Otras son de Alemania: Fráncfort (Städelsches Kunstinstitut) y Berlín algún museo ha recibido por el préstamo es considerable, acorde con la categoría de la obra prestada y su papel en el conjunto de sus fondos, tal como ocurre con el tríptico procedente del Museu Nacional de Arte Antiga de Lisboa, lo que ha supuesto que actualmente no se pueda ver en el Prado el Autorretrato de Durero. Algunas obras consideradas de El Bosco no han venido a la exposición del Museo del Prado, como la Crucifixión con donante del Koninklijk Museum voor Schone Kunsten de Bruselas, el muy dañado tríptico de los Santos ermitaños (Gallerie dell'Accademia, Venecia) y el tríptico de El Juicio Final de Viena, pieza que, no obstante, no ha dejado de estar revestida de polémica.

La exposición del Museo del Prado presenta a El Bosco en su doble faceta artística, pintor y dibujante. Siete son las hojas con dibujos que se muestran en las paredes de las salas como originales de El Bosco, dos más se consideran de taller, otro par, de seguidores, y un dibujo se presenta como obra probable del artista. Algunos están realizados por ambas caras, con tinta parda a pluma como técnica predominante, a veces agrisada a pluma y pincel así como con realces de albayalde. Diversas obras de autores diferentes complementan ciertos aspectos del discurso expositivo, como una tabla de un autor anónimo, detalles escultóricos de un retablo, grabados a buril, un par de libros con miniaturas y una copia del Comentario de la pintura y pintores antiguos, de Felipe de Guevara, quien poseyera, por herencia de su padre, El carro de heno (El Escorial).

Todos los cuadros pintados por El Bosco están realizados sobre madera, de roble, como es habitual en el norte, a excepción de La mesa de los Pecados Capitales, cuyo soporte es de chopo, probablemente para aligerar su peso ante su uso, aún desconocido. Estamos frente a tablas sueltas y otras que configuran trípticos, siguiendo la estela del siglo Xv. Es interesante comprender cómo el tríptico de la Adoración de los Magos, de c. 1494 (Museo del Prado), conserva su marco original, ${ }^{9}$ con sus bisagras, y el que muestra escenas de la Pasión de Cristo, de c. 1520-1530 (Museu de Belles Arts de València), la guarnición que protege el ensamblaje. Tablas sueltas pudieron formar parte de muebles litúrgicos de cierta entidad, como trípticos, incluso dípticos. Así, se desconoce la estructura original de las cuatro piezas verticales que constituyen las Visiones del Más Allá (c. 1505-1515), del Palazzo Ducale de Venecia. Hay que tener en cuenta que algunas unidades están pintadas por ambas caras, por lo

(Staatliche Museen zu Berlin, Gemäldegalerie). Viena ha contribuido con obras del Kunsthistorisches Museum, Gemäldegalerie, de la Albertina y de la Akademie der Bildenden Künste, Graphische Sammlung. De Londres participan la National Gallery y el British Museum, así como The Bodleian Libraries, University of Oxford, de Oxford. Otras piezas proceden del Musée du Louvre, del Musée Municipal de SaintGermain-en-Laye y del Palais des Beaux-Arts de Lille. Obras de El Bosco también han venido de Venecia (Palacio Ducal, Gallerie dell'Accademia). De Lisboa (Museu Nacional de Arte Antiga) procede uno de sus trípticos singulares, mientras que varias son las colecciones norteamericanas que han cedido piezas: Metropolitan Museum de Nueva York, National Gallery of Art de Washington, Philadelphia Museum of Art de Filadelfia, The J. Paul Getty Museum de Los Ángeles, Museum of Fine Arts de Boston, Yale University Art Gallery de New Haven, CT, y The Nelson-Atkins Museum of Art de Kansas City, MO.

9. Fracturado, a finales del siglo XIX se le añadieron fragmentos de pino. 
que pudieron ser parte de dípticos o trípticos. Es el caso de Cristo camino del Calvario, con El Niño Jesús jugando en el reverso, o cara externa (c. 1505/1510-1516), del Kunsthistorisches Museum de Viena, que, cortada por la parte superior e inferior, fue la puerta izquierda de un tríptico. ${ }^{10}$ Sobre San Cristóbal con el Niño Jesús a cuestas (c. 1490-1500), del Museum Boijmans Van Beuningen de Róterdam, hay dudas acerca de su carácter independiente o su pertenencia a la tabla central de un tríptico. Otra hipótesis se presenta ante las tablas con San Juan Bautista en meditación (1485-1510), del Museo Lázaro Galdiano, y San Juan Evangelista en Patmos (c. 1505), de Berlín (Staatliche Museen zu Berlin, Gemäldegalerie) - pintada por el reverso con un círculo con escenas de la Pasión de Cristo-, según algunos probables puertas de un tríptico y no en vano las tablas se muestran consecutivamente en la exposición del Prado. ${ }^{11}$ La exposición del Prado nos ofrece la oportunidad de ver juntas tablas que formaron parte de un tríptico desmembrado, el denominado El camino de la vida (c. 1505-1516), las cuales se conservan en cuatro colecciones diferentes, todas pintadas sobre madera procedente del mismo árbol. En realidad, dos elementos fueron cortados horizontalmente de una de las alas: La nave de los locos (Musée du Louvre, París) y La alegoría de la intemperancia (Yale University Art Gallery, New Haven, CT), pareja de La muerte y un avaro (National Gallery of Art, Washington), el único elemento que conserva su formato original, mientras que El vendedor ambulante (Museum Boijmans Van Beuningen, Róterdam) es el resultado de haber serrado verticalmente las tablas laterales, de manera que se desconoce la tabla central del mueble.

Las obras de El Bosco están realizadas al óleo y en el caso de los trípticos y probables puertas sueltas el reverso de las mismas se pinta en grisalla o semigrisalla. La exposición del Museo del Prado facilita contemplar estas sin ninguna dificultad, al estar situados los trípticos sobre pedestales que permiten que el visitante dé toda la vuelta alrededor y las probables puertas sueltas en otros ubicados en aberturas que forman parte del montaje. ${ }^{12}$

Pocas son las obras firmadas por El Bosco. ${ }^{13}$ Otro problema reside en la propia autoría. De ninguna de las que han

10. Se especula que en la tabla central se mostraría un Calvario, mientras que en la otra ala habría un Descendimiento de la cruz o un Santo Entierro.

11. La idea de que formaran pareja es desechada en el catálogo de la exposición, apoyando opiniones ya formuladas y aduciendo, entre otros aspectos, la imposibilidad de comprobar que la tabla del Lázaro estuviera pintada por su cara externa, la cual ha sido rebajada y engatillada. También se ha apuntado que fueran postigos interiores del retablo escultórico de Adriaen van Wesel realizado por encargo de la cofradía de Nuestra Señora, en la catedral de San Juan, de 's-Hertogenbosch. San Juan en Patmos era el emblema de la hermandad de Nuestra Señora. De hecho, Koldeweij ha reconstruido la estructura general del retablo y conjetura que la tabla de Madrid tenía que estar también pintada en el reverso, tal vez con el Nacimiento y la Juventud de Jesús, al tener en la de Berlín escenas de la Pasión.

12. Tal es el caso de San Juan Evangelista en Patmos / Pasión de Cristo, de la Gemäldegalerie de Berlín.

13. Curiosamente, su pieza cumbre, El jardín de las delicias $(\mathrm{Mu}-$ seo del Prado) no lo está. JHERonimus Bosch aparece en diversas piezas, como el tríptico de la Adoración de los Magos (c. 1494), del citado museo; el de Santa Wilgefortis (1495-1505), de las Gallerie dell'Accademia de Venecia; el de Las tentaciones de san Antonio Abad llegado hasta la actualidad se conserva documentación de su encargo. En realidad son escasas las referencias que existen sobre la actividad del artista, que se asocia a los tiempos convulsos que se vivieron en Flandes en la segunda mitad del siglo xvi y en la siguiente centuria y que ha conllevado la desaparición de información escrita. Al ser miembro de la cofradía de Nuestra Señora y de la Ilustre Hermandad de Nuestra Señora, en su localidad natal de 's-Hertongebosch, de la que se conserva sus cuentas, hay ciertas menciones a su labor artística, también a través de la cofradía de la Tabla del Espíritu Santo. Un encargo de envergadura fue el que recibió en 1504 por parte de Felipe el Hermoso, un Juicio Final, en el que se especifica su nombre y sobrenombre, así como su residencia, Jheronimus van Aken, llamado Bosch, obra perdida, si es que realmente se llegó a pintar.

La crítica siempre ha estado dividida acerca de la autoría de un buen número de obras de El Bosco. En cuanto a las del Museo del Prado, nunca se ha cernido la duda sobre la Adoración de los Magos y El jardín de las delicias, pero sí, incluso, sobre El carro de heno, La mesa de los Pecados Capitales y Las tentaciones de san Antonio Abad. Por lo que respecta a los dibujos, se consideran obras indiscutibles el Nido del búho de Róterdam y el Hombre-árbol de Viena. Las atribuciones han ido bailando entre diferentes investigadores, y si en el caso del tríptico de El carro de heno el BRCP lo ha situado como obra original, también se ha adscrito al Maestro del carro de heno, en torno al cual se han situado otras obras. Por tanto, estamos ante obras de El Bosco, obras de El Bosco con dudas (tal es el dibujo del Entierro de Cristo, de $c .1505-1515$, British Museum, Londres), de El Bosco y taller (incluso, con dudas sobre la intervención del taller) -como la Adoración de los Magos (1495-1516) del Philadelphia Museum of Art que el BRCP da como de taller exclusivamente-, ante obras del taller o discípulo, ${ }^{14}$ incluso ya fallecido el maestro (tríptico con escenas de la Pasión de Cristo del Museu de Belles Arts de València, c. 1520-1530), ante obras de un seguidor - como ocurre con el tríptico con Escenas de Job (c. 1510-1515), del Groeningemuseum de Brujas, obra de taller según el BRCP-, ante obras del taller o de un seguidor, en el marco del cual, según el BRCP estaría La mesa de los Pecados Capitales, o claramente ante obras de un seguidor, donde se encontraría Las tentaciones de san Antonio Abad del Museo del Prado, la Coronación de espinas de El Escorial y el tríptico de la Pasión de Cristo de Valencia, también según el BRCP. La citada Las tentaciones de

de Lisboa; la probable puerta de tríptico con San Juan Evangelista en Patmos (c. 1505) de la Gemäldegalerie de Berlín; la tabla central del tríptico de El Juicio Final de Brujas (1505-1515)... También lleva firma La mesa de los Pecados Capitales, del Prado, que el BRCP ha considerado de un seguidor. El tríptico de El carro de heno (c. 1512-1515) del mismo museo también está firmado, pero igualmente su copia de El Escorial. No sería autógrafa la firma que aparece en la tabla central del tríptico con escenas de la Pasión de Cristo del Museu de Belles Arts de València (c. 1520-1530), hecho por un discípulo de El Bosco, activo incluso tras su muerte, como vemos, firma que habría que entender, según el catálogo de la exposición, «como una marca o sello del obrador y no como una firma autógrafa».

14. Tal como se especifica en el catálogo de la exposición, es interesante comparar la tabla con el Ecce Homo (c. 1485-1495) de Fráncfort (Städel Museum) y el mismo tema pintado por el taller hacia 1500 (Museum of Fine Arts, Boston). 
san Antonio Abad ha sido un cuadro considerado por Fischer (2013) obra de taller o seguidor, bajo la adscripción con interrogante a un «Pupil of Hieronymus Bosch», tal como el tríptico de El Juicio Final del Groeningemuseum de Brujas. También se habla de copias (como la de El carro de heno de El Escorial con respecto al ejemplar del Prado) y de copias o interpretaciones de originales perdidos, como sucede, según el BRCP, con La extracción de la piedra de la locura del Prado, considerada por el referido equipo copia de un original que El Bosco realizó a partir de 1481.

Según el catálogo de la exposición del Museo del Prado, los originales de El Bosco se cifran en una cantidad que va de veintiuno a veinticinco, estableciéndose las bases para definir su lenguaje a partir de los trípticos de la Adoración de los Magos y Eljardín de las delicias, realizados con anterioridad a 1500, y el de El carro de heno (c. 1512-1515), obra tardía, todas en el referido museo.

Por otra parte, ninguna obra de El Bosco está fechada y se considera extraordinariamente difícil datar con seguridad alguna de ellas. Se habla de obras juveniles (como la Adoración de los Magos del Metropolitan Museum de Nueva York, de hacia 1474 o después), o tardías (como el tríptico de El carro de heno, de hacia 1512-1515, del Prado), dándose cronologías muy dilatadas, como las Visiones del Más Allá, de hacia 1505-1515 (Palazzo Ducale, Venecia). Algunas fechas han sido adelantadas, basándose en planteamientos estilísticos (al estar próxima a la Adoración de los Magos del Prado) y técnicos, como El jardín de las delicias, que la guía de la Pintura flamenca de los siglos XV y XVI de $2001^{15}$ considera que se trata de una obra pintada hacia 1500-1510 mientras que actualmente se adscribe a 1490-1500.

Así como deficientes restauraciones han deteriorado la calidad de ciertas obras, este procedimiento y la técnica puesta al servicio del análisis y diagnóstico de la obra de arte han contribuido al mejor conocimiento de la labor creativa de El Bosco, afinando atribuciones y postulando nuevas cronologías. Algunas tablas se presentan en la exposición del Museo del Prado recientemente restauradas, tal es el caso de San Cristóbal con el Niño Jesús a cuestas, del Museum Boijmans Van Beuningen de Róterdam, el San Jerónimo penitente de Gante (Museum voor Schone Kunsten), La nave de los locos del Louvre, el Camino del Calvario de Viena (Kunsthistorisches Museum), la Adoración de los Magos de Filadelfia (Philadelphia Museum of Art), las Visiones del Más Allá, de Venecia (Palazzo Ducale), el tríptico de los Santos ermitaños de las Gallerie dell'Accademia de Venecia, el de Santa Wilgefortis, del mismo museo, el de El Juicio Final de Brujas (Groeningemuseum) y el tríptico de la Adoración de los Magos, restaurada su capa pictórica por Herlinda Cabrero e intervenida la estructura del mueble por José de la Fuente, además de la cuestionada Las tentaciones de san Antonio Abad, restaurada por María Antonia López de Asiaín, ${ }^{16}$ todos ellos miembros del equipo de restau-

15. Redactada por la comisaria de la exposición, Pilar Silva Maroto.

16. José de la Fuente, María Jesús López (restauradora de marcos) y Herlinda Cabrero comentan en un vídeo el proceso de restauración, disponible en https://www.museodelprado.es/actualidad/multime $\mathrm{dia} /$ restauracion-el-triptico-de-la-adoracion-de-los/aa6f23fd-ef54- radores del Museo del Prado, donde se conserva la obra, que han realizado una labor prodigiosa.

La dendrocronología, que estudia la datación de los anillos de crecimiento de las plantas arbóreas y arbustivas leñosas, es una ciencia que se ha ido aplicando a los soportes de roble empleados por El Bosco. ${ }^{17}$ Así pues, es posible conocer la fecha de la tala del árbol a partir de la cual es absolutamente seguro situar el cuadro en cuestión, independientemente del tiempo, a veces muy dilatado, que transcurre entre el corte y el empleo de esa madera, mediando años de secado y/o almacenaje. Evidentemente, un árbol talado después de la muerte de El Bosco no puede originar de ninguna manera un original. A pesar de que este pudo llevar a cabo El jardín de las delicias después de 1466, su ejecución corresponde a 1490-1500, del mismo modo que para La extracción de la piedra de la locura, del mismo museo madrileño, el árbol fue talado en 1486, cuando El Bosco no pintó el cuadro hasta la lejana fecha de 1501-1502. Interesante es el hecho de que se haya podido constatar que La nave de los locos, La alegoría de la intemperancia, La muerte y un avaro y El vendedor ambulante, todas en diferentes museos (París, New Haven, Washington, Róterdam), son tablas procedentes del mismo árbol. En cambio, no pertenecen a madera del mismo árbol las que llevan la representación de San Juan Bautista en meditación, del Museo Lázaro Galdiano, y San Juan Evangelista en Patmos, de Berlín, que se supusieron elementos de un mismo conjunto.

Si la luz visible permite el estudio de la capa pictórica, la radiación infrarroja tiene mayor longitud de onda y la atraviesa desvelando el dibujo subyacente. Los rayos X traspasan todos los estratos, incluso captan el bastidor. En los últimos años los museos desarrollan análisis con estos recursos técnicos llegando a diagnósticos de extraordinaria valía. El Gabinete de Documentación Técnica del Museo del Prado viene trabajando intensamente en este complejo y sorprendente terreno, ${ }^{18} \mathrm{y}$ tal ocurre con un artista como El Bosco. Carmen Garrido - quien fuera jefa de dicha área del Prado- ha venido trabajando en la obra de El Bosco bajo esta perspectiva desde la década de los ochenta, sola o en colaboración con Roger van Schoute, quien ha estudiado el dibujo subyacente desde los años sesenta. Hay que mencionar sus investigaciones publicadas en el catálogo de la exposición El jardín de las delicias de El Bosco: copias, estudio técnico y restauración, celebrada en el Prado (2000), así como la monografía especial que ambos le dedicaron a las

46e8-9109-8dc29e67c8eb, mientras que en otro, en colaboración con la comisaria de la exposición, María Antonia López de Asiaín describe su intervención, disponible en https://www.museodelprado.es/ actualidad/multimedia/las-tentaciones-de-san-antonio-abad-delbosco/1624b639-ccfa-48db-acb4-5e7obfo28019.

17. Precisamente un sombrero de uno de los esbirros de la Coronación de espinas de la National Gallery de Londres lleva por decoración unas hojas de esta especie. Como referentes en este tipo de exámenes está la exposición sobre El Bosco llevada a cabo en 2001 en el Museum Boijmans Van Beuningen de Róterdam, comisariada por Jos Koldeweij, con estudios sobre el particular de Peter Klein.

18. Es obligatorio mencionar la exposición organizada en el Museo del Prado en 2006 bajo el título El trazado oculto. Dibujos subyacentes en pinturas de los siglos XV y XVI, con la edición del catálogo a cargo de Gabriele Finaldi y Carmen Garrido. 
obras de El Bosco conservadas en el referido museo (2001). A las reflectografías infrarrojas se suman las radiografías, y la fotografía de alta resolución permite un estudio más exhaustivo de la obra de El Bosco, todo ello material técnico que se ha llevado a cabo nuevamente en las piezas del $\mathrm{Mu}-$ seo del Prado con motivo del V Centenario, ${ }^{19}$ ahora con medios que aportan mayor precisión y facilitan enormemente la «lectura» del documento técnico. ${ }^{20}$ El digitalizado de las placas radiográficas y el tratamiento digital para la eliminación de los barrotes del reverso, incluso del engatillado, han permitido una imagen más nítida del procedimiento artístico de las obras de El Bosco. Además del Museo del Prado, también el equipo del Bosch Research and Conservation Project ha realizado nuevamente estudios de este tipo, con resultados recogidos en su catálogo razonado y en un volumen aparte (2016), en donde se hacen constantes comparaciones para estudiar la obra y legitimar sus atribuciones. En definitiva, todo este conjunto de documentos han permitido incluso la reconsideración de ciertas cronologías. La exposición del Museo del Prado no ha ocultado al público este material, aunque lo ha mostrado en una mínima parte: se ha podido ver la reflectografía y la radiografía de El jardín de las delicias (con el engatillado suprimido digitalmente), así como las radiografías de San Juan Bautista en meditación, del Museo Lázaro Galdiano, y de Las tentaciones de san Antonio Abad, del Prado, con explicaciones en castellano e inglés.

Sobre una preparación blanca de creta extendida encima del soporte, El Bosco lleva a cabo el dibujo inicial de su composición pictórica. ${ }^{21}$ En los últimos años el análisis del dibujo subyacente ha facilitado reforzar la autoría de ciertas obras cuestionadas. Al respecto, el estudio de estos dibujos que a veces han salido a la superficie pictórica ha hecho posible la incorporación al catálogo de El Bosco de Las tentaciones de san Antonio Abad (fragmento), de hacia 15051510, del Nelson-Atkins Museum of Art (Kansas City, MO). Asimismo, las modificaciones que se observan en el dibujo subyacente de la Adoración de los Magos del Metropolitan Museum implican que no estamos ante una copia a pesar de las dudas que se han cernido sobre ella. No solamente la técnica ha desvelado cambios en la fase del dibujo subyacente, ${ }^{22}$ sino entre este y la ejecución pictórica. Las rectificaciones y los desplazamientos son habituales en los dibujos subyacentes de El Bosco. Precisamente estas modificaciones son indicio de que se trataría de originales. Es uno de los motivos aducidos por el Museo del Prado

19. En este terreno hay que mencionar a Laura Alba, Jaime García-Máiquez, María Dolores Gayo y Maite Jover.

20. Se ha pasado de usar una cámara vidicón a un sensor CCD, del tipo InGaAs, sensible al IE, equipado con OSIRIS (Optical Space Infrared Dowlink System). En cuanto a las radiografías, las placas de formato $120 \times 90$ se han visto desplazadas por las tiras, que pueden llegar a gran cantidad de metros de longitud, con la posibilidad de lograr una imagen a escala 1:1.

21. No siempre tiene por qué haber dibujo subyacente, así, la grisalla de las caras externas de las puertas del tríptico de la Adoración de los Magos (Museo del Prado) está pintada directamente, sin dibujo previo, a diferencia de los anversos.

22. Como sucede con El Paraíso y la tabla central de El jardín de las delicias, descubiertos con motivo de los recientes análisis técnicos. para defender como tal La mesa de los Pecados Capitales (c. 1505-1510), ${ }^{23}$ así como La extracción de la piedra de la locura. El nuevo material técnico con el que ha trabajado el Prado ha permitido comprobar modificaciones en la tabla central del tríptico de la Adoración de los Magos, como el desplazamiento de san José hacia la tabla lateral, un aspecto que afecta a lecturas de índole iconográfica. Asimismo, los nuevos equipos de reflectografía infrarroja han desvelado un dibujo subyacente en Las tentaciones de san Antonio Abad del Museo del Prado, cuando hace unos años apenas se pudo detectar.

Los donantes ocultos es un aspecto interesante en la producción de El Bosco, que las reflectografías infrarrojas y las radiografías ponen al descubierto, como se ha podido apreciar desde hace años con el oculto por una planta en San Juan Bautista en meditación (c. 1489 o después), del Museo Lázaro Galdiano, ${ }^{24}$ o los que hay debajo de San Antonio en meditación y Monje conduciendo a un soldado, tablas laterales del tríptico de Santa Wilgefortis, de 1495-1505 (Gallerie dell'Accademia, Venecia). Por su parte, la Coronación de espinas de la National Gallery de Londres está pintada sobre un San Cristóbal cruzando el río con el Niño a hombros. La técnica también ha revelado que el remate de Las tentaciones de san Antonio Abad, del Museo del Prado, era circular, transformado en adintelado en el siglo XIX, de tal manera que en la exposición se halla expuesto camuflando las esquinas falsas.

Teniendo en cuenta los problemas cronológicos de las obras de El Bosco, el Museo del Prado ha optado para la exposición por una presentación de índole temática, desplegada en la planta baja de la ampliación de los Jerónimos (Salas A y B). La sección I. El Bosco y 's-Hertogenbosch sitúa al artista en el contexto social y artístico de su localidad natal, donde Jheronimus van Aken aparece primeramente mencionado en relación con su oficio de pintor el 26 de julio de 1474. Prueba de la consideración que ya tuvo en el mismo siglo Xvi es el buril (c. 1565) que le representa, grabado por Cornelis Cort en una serie de efigies de pintores célebres de los Países Bajos publicada en 1572, con un poema en latín en la parte baja en que se menciona sus ojos y su mano, pero también las figuras monstruosas que caracterizan sus obras. Conocida actualmente como Den Bosch, la que en castellano denominamos Bolduque era una de las ciudades más importantes del ducado de Brabante, con provincias actualmente ocupadas por Bélgica y los Países Bajos. Ocupada por la dinastía borgoñona y posteriormente por la de los Habsburgo, en ella trabajó su padre y hermanos, puesto que su progenitor ya formaba parte de una familia de pintores, al parecer procedente de Aquisgrán. La plaza del Mercado era un punto de actividad comercial y social en donde precisamente vivía su familia — ya desde 1462-, y él tuvo casa propia en el lado opuesto, adquirida

23. Se operan entre la fase de dibujo y la de color, aparte de los numerosos cambios que se observan en la ejecución pictórica.

24. Estudios técnicos de la tabla llevados a cabo por el Instituto Histórico en 1995 y recientemente por el Bosch Research. Existe un visor interactivo de la obra en que se pueden apreciar las diferentes técnicas que se le han aplicado para el análisis de la obra, disponible en http://www.boscointeractivo.es/. 
por su esposa, Aleid van de Meervenne, con quien ya debía estar casado en 1480 . Probablemente también era su taller propio el hogar matrimonial, que aparece en una tabla representando el referido mercado en el contexto de una escena religiosa. Aparte de la bulliciosa vida en torno a la plaza que de alguna manera pudo haber influido en sus obras, por 's-Hertogenbosch pasaron ilustres personajes, como Carlos el Temerario, María de Borgoña, Maximiliano de Austria, su hijo Felipe el Hermoso, duque de Brabante, casado con Juana de Aragón, Margarita de Austria... Al igual que El Bosco, también era miembro de la cofradía de Nuestra Señora de la iglesia de San Juan el notario y secretario municipal Peter van Os, quien aparece con otros miembros de la familia como donante en el tríptico del Ecce Homo (c. 1500), obra de taller conservada en el Museum of Fine Arts de Boston. El padre de El Bosco y sus hijos fueron llamados a propósito del diseño de un retablo de talla con sus puertas pintadas. Relacionado con el mismo, se presentan en la exposición dos fragmentos escultóricos (c. 1476-1477), debidos a Adriaen van Wesel. ${ }^{25}$ Las estampas de Alart du Hameel sitúan en el marco de esta ciudad a un grabador, escultor y arquitecto, en donde trabajó entre 1478 y 1494, y en cuyas estampas suele introducir junto con su anagrama la palabra «bosche», como una firma más, alusiva a 's-Hertogenbosch.

La sección II. Infancia y vida pública de Cristo acoge obras pictóricas con tres epifanías, aparte de un dibujo de un seguidor representando las Bodas de Caná (Musée du Louvre, París). La del Museo del Prado (c. 1494) fue un encargo del deán de la guilda de pañeros de Amberes ${ }^{26}$ quien aparece en el tríptico junto con otros miembros de la familia, conocidos a través de los escudos de armas; ${ }^{27}$ se trata de una obra de extraordinaria calidad en el conjunto de su producción, de la que se desconoce cómo llegó a ser propiedad de Felipe II. Como temprana creación se considera la Adoración de los Magos del Metropolitan de Nueva York, la cual ha dejado de ser de taller o seguidor tras exhaustivos estudios de tipo técnico, particularmente de su dibujo subyacente. En cambio, la autoría de la del Philadelphia Museum of Art es objeto de dudas, tal como recoge la cartela y el catálogo de la exposición.

III. Los santos es el enunciado bajo el cual se despliega una serie de obras con la representación de santos habituales en la producción de El Bosco. El tríptico con una barbuda crucificada se considera de santa Wilgefortis ( $c$. 14951505), conservado en las Gallerie dell'Accademia de Venecia, con donantes ocultos en las tablas laterales. San Jerónimo en oración, de c. 1490-1500 (Museum voor Schone Kunsten, Gante), fue en su momento atribuido a un seguidor (Maestro del carro de heno). Acompañado de sus atributos, su disposición física demuestra su absoluta entrega a

25. Se ha llegado a pensar que las puertas correspondan a las tablas con San Juan Bautista en meditación (Museo Lázaro Galdiano, Madrid) y San Juan Evangelista en Patmos (Gemäldegalerie, Berlín).

26. Se ha especulado si El Bosco viajó a esa ciudad, posibilidad que se considera innecesaria en el catálogo de la exposición.

27. La identificación de los donantes a través de los escudos ha sido relativamente reciente, en 2004, lo cual ha permitido ajustar la cronología de la obra.
Cristo a través de la oración y las privaciones materiales. Alejado del mundo, también en varias ocasiones El Bosco representa a san Antonio Abad, otro de sus modelos de conducta. El tríptico del Museu Nacional de Arte Antiga (c. 1500-1505) es una de las obras más sorprendentes del artista, en cuyas tablas se despliega el mundo del santo sacudido por situaciones y seres que ponen a prueba la fortaleza de su fe. La exposición del Prado reivindica Las tentaciones de san Antonio Abad (c. 1510-1515) de sus propios fondos como obra original: tabla modificada no solamente en el formato sino mediante repintes ( $\sin$ barniz intermedio), barnices teñidos y deterioros de la capa pictórica, su reciente restauración ha desvelado elementos imperceptibles hasta ahora, como el humo del fuego que arde tras el tronco del árbol. Por el contrario, otra tabla con el mismo asunto (c. 1510-1515) conservada en el mismo museo corresponde a una obra de taller. Job, con el valor de la paciencia como principio vital, es otra de las figuras de la devotio moderna. El tríptico que se conserva en Brujas se considera obra de un seguidor. San Cristóbal con el Niño Jesús a cuestas (c. 1490-1500), del Museum Boijmans Van Beuningen de Róterdam, tabla independiente o parte central de un tríptico, cuenta con elementos pictóricos incorporados en una fase cercana del final de la ejecución, sin dibujo subyacente. Los santos Juanes también se encuentran en la iconografía de El Bosco, tal como vemos en los ejemplares de San Juan Bautista en meditación (Museo Lázaro Galdiano, Madrid) y San Juan Evangelista en Patmos (Gemäldegalerie, Berlín), sobre las que se ha especulado que fueran las puertas del retablo escultórico encargado por la cofradía de Nuestra Señora en la iglesia de San Juan de 's-Hertogenbosch, lo cual rechaza el catálogo de la exposición.

En el tema que la exposición titula IV. Del Paraíso al Infierno, el tríptico de El carro de heno (c. 1512-1515) del Museo del Prado destaca sobremanera; se trata de una de sus últimas creaciones cuyo carácter de original la institución refuerza mediante la documentación técnica y la dendrocronología. Escenas «infernales» dan paso al tríptico de $E l$ Juicio Final (c. 1505-1515) de Brujas (Groeningemuseum), con configuraciones tremendistas del infierno tanto en la tabla central como en la derecha. Una de las imágenes más divulgadas de El Bosco corresponde a la Ascensión al Empíreo, donde las almas van subiendo hacia el Paraíso Terrenal a través de un túnel, viéndose la espiritual luz intensa a lo lejos. Forma parte de un conjunto con Visiones del Más Allá (c. 1505-1515), de las Gallerie dell'Accademia de Venecia, con un simbólico hombre melancólico en la Caída de los condenados que alude a la profunda tristeza que se genera en el alma del pecador.

El jardín de las delicias (c. 1490-1500) configura un tema expositivo único (sección v). El hecho de que cuelgue junto a este tríptico el dibujo del Hombre-árbol (c. 1500-1510) se debe a la presencia de esta configuración en la puerta del Infierno. A pesar de que no está firmado, se trata de la obra paradigmática de El Bosco, confiscada por el duque de Alba a Guillermo de Orange de su palacio de Coudenberg, en Bruselas, y actualmente considerada un encargo de su tío Engelbrecht II, conde de Nassau. Comprada por Felipe II en la almoneda del hijo ilegítimo de aquel, Fer- 
nando de Toledo, en 1591, fue destinada a El Escorial. Adelantada a la década de los noventa por su vinculación estilística con la Adoración de los Magos ${ }^{28}$ ha sido objeto de innumerables lecturas, permaneciendo prácticamente inalterable la idea de la perdición del ser humano a través del consumo de los placeres terrenales, un falso Paraíso que se expresa terriblemente elocuente en los castigos que se recibe en el Infierno. ${ }^{29}$ Destacado personaje de la corte de Borgoña, hombre culto y miembro de la cofradía de Nuestra Señora, en 's-Hertogenbosch, al igual que El Bosco, una vitrina de la exposición acoge un retrato de Engelbrecht II, con su collar de la orden del Toisón de Oro, ${ }^{30}$ su Libro de Horas, con miniaturas iluminadas sobre pergamino (The Bodleian Libraries, University of Oxford), así como un ejemplar iluminado de Les visions du chevalier Tondal (1475), probable fuente para obras de El Bosco al constituir un relato sobre el Más Allá.

El mundo y el hombre: pecados capitales y obras profanas es la sección vi de la exposición del Museo del Prado. La mesa de los Pecados Capitales (1505-1510) se presenta como tal, en sentido horizontal, en un tiempo colgada en el referido museo como cuadro, ${ }^{31}$ aunque el propio catálogo indique que se ignora la verdadera función de este chopo, del que se han hecho estudios técnicos a través de los cuales el museo avala su autoría, cuestionada por el BRCP, para el cual se trata de una obra de taller o seguidor, adscripción esta última en que se exponen otros cuadros procedentes de colecciones extranjeras. El Nido del búho (c. 1505-1515), del Museum Boijmans Van Beuningen, y la Escena burlesca con un hombre en un canasto (c. 1510-1515), de la Albertina de Viena, están entre los dibujos más exquisitos de El Bosco, peculiares dentro de su lenguaje simbólico. La extracción de la piedra de la locura (c.1501-1505) es una obra sin ningún sentido sacro pero sí moralizante, en la que lo que el falso doctor saca de la cabeza es un tulipán de lago. Conservada en el Museo del Prado, se considera que fue un encargo de Felipe de Borgoña, hijo ilegítimo del duque Felipe el Bueno, fundador de la Orden del Toisón de Oro, ${ }^{32}$ si bien el BRCP la considera de un seguidor a partir de un original perdido. El tríptico de El camino de la vida (c. 1505-1516) - como ya hemos indicado, parte de un conjunto desmembrado- muestra temas alegóricos relativos a la vida, a la necedad del ser humano, a su recorrido vital y a la muerte, en el contexto moralizante del lenguaje de El Bosco: su Vendedor ambulante (Museum Boijmans Van Beuningen) conecta con las caras externas de El carro de heno del Museo del Prado, una imagen del ser humano en el camino de la cas.

28. Además de por su relación con determinadas fuentes grá-

29. Poniéndose énfasis en la fragilidad del disfrute carnal, este engañoso Jardín del Amor se ha puesto en relación (Falkenburg) con el Jardín del Placer del Roman de la rose, poema alegórico del siglo XIII, interpretándose el tríptico como una obra que propiciaba la conversación en torno al ars amandi.

30. Fue gobernador de los Países Bajos (1485-1486) en nombre de Felipe el Hermoso.

31. Disposición defendida por Joaquín Yarza (YARZA, J., El jardín de las delicias. Madrid: Tf., 1998, pág. 28).

32. De hecho, la ornamentación e inscripciones conectan con los escudos de la Orden. vida, cuyas insospechadas e ingratas vicisitudes debe ir sorteando.

La Pasión de Cristo es la viI y última sección de la exposición de El Bosco en el Museo del Prado. Cristo camino del Calvario (c. 1505/1510-1516) es una escena de una puerta de un tríptico que tiene por su cara externa el Niño Jesús jugando, avanzando con un andador y un molinillo de viento, cándida imagen que ha despertado diversas interpretaciones. De Valencia procede el tríptico con escenas de la Pasión de Cristo (c. 1520-1530), obra de taller o seguidor (en realidad se advierte más de una mano) a pesar de su firma, que perteneciera a Mencía de Mendoza, la cual contrajo matrimonio con el conde Hendrick III de Nassau, propietario de El jardín de las delicias. La exposición se va cerrando con el Ecce Homo procedente de Fráncfort (c. 1485-1495), con donantes parcialmente eliminados y repintados, la Coronación de espinas (c.1510) de la National Gallery de Londres y Cristo camino del Calvario (c. 1500) de Patrimonio Nacional.

La exposición del Museo del Prado combina la línea recta de los muros con la curvilínea, huyendo de la organización ortogonal. ${ }^{33}$ Altos y dilatados pedestales ofrecen la posibilidad de contemplar las caras externas de los trípticos mientras que otras piezas se protegen en vitrinas murales, siendo particularmente interesante las oquedades murales sobre las que se disponen piezas sueltas trabajadas por ambas caras. La información de la pieza es básica, sin el aporte cronológico, si bien se echa en falta mayor información complementaria en cada una de las secciones.

Pilar Silva Maroto, jefa del Departamento de Pintura Flamenca y Escuelas del Norte (1400-160o) y Pintura Española (1100-1500), es la comisaria de la exposición, tal como lo fue en la de 2000, dedicada a El jardín de las delicias. A ella se debe en gran medida el catálogo de la exposición, en el que han colaborado estudiosos de El Bosco. ${ }^{34}$ El folleto de sala realiza un amplio comentario de las 53 piezas expuestas, contando como oferta opcional una audioguía con 17 obras seleccionadas.

La página web del Museo del Prado ofrece el apartado de «Obras comentadas», en el que intervienen jefes de conservación (Pilar Silva Maroto, Alejandro Vergara), el director-adjunto de Conservación e Investigación (Miguel Falomir) y miembros del Gabinete de Documentación Técnica y del Taller de Restauración. El jardín de las delicias, como motivo de conversación, centra el documental bajo la dirección de José Luis López Linares, el cual se estrenó en diferentes salas el 9 de junio: El Bosco, el jardín de los sueños es su título y en él intervienen distintas personalidades de la cultura.

Jardín infinito ( 4 de julio - 2 de octubre de 2016) corresponde a una videoinstalación con 18 canales, de 9.000 lúmenes cada uno, y 16 pistas de sonido, gracias a la cual se proyectan macroimágenes de El jardín de las delicias sobre los muros de la sala C (ampliación de los Jerónimos), que se transforman en pantallas de 20 metros de largo y

33. El diseño y dirección del montaje se debe a El Taller de GC. 34. Eric De Bruyn, Paul Vandenbroeck, Larry Silver, Reindert Falkenburg y Fernando Checa Cremades. 
6 de alto, con una duración de 75 minutos. El cineasta Andrés Sanz, los músicos Javier Adán y Santiago Rapallo y el artista Álvaro Perdices llevan a cabo una creación artística de imágenes y sonidos transformando la obra original en pro de lo meramente visual y lo sensorial, deconstruyéndola para que quien la contempla se traslade al terreno de lo onírico. ${ }^{35}$ Con motivo del V Centenario de El Bosco, el Museo del Prado ha editado un cómic (72 páginas, $18 \times 26 \mathrm{~cm}$ ) bajo el título El tríptico de los encantados (Una pantomima bosquiana) (2016), inspirado en tres obras del autor conservadas en el citado museo. Se debe a Max (Francesc Capdevila) (Barcelona, 1956), autor de historietas e ilustrador,

35. Otros artistas contemporáneos han llevado a cabo en Madrid exposiciones ligadas a El Bosco. En Manuel Ballester. Paisajes encontrados: El Bosco, El Greco y Goya (Museo Lázaro Galdiano, hasta el 11 de septiembre de 2016), el fotógrafo suprime la figura y los animales de San Juan Bautista en meditación de El Bosco, ofreciendo exclusivamente el paisaje. Artilugios bosquianos: Sjon Brands es un
Premio Nacional de Cómic 2007. Un ciclo de conferencias y otro de cine, así como un concierto de música de la época de El Bosco cierran, de momento, los acontecimientos vinculados al Museo del Prado con motivo del V Centenario de su muerte, además del curso El Bosco: 500 años, organizado por la Fundación Amigos del Museo del Prado.

Silva Maroto, P. (ed.), El Bosco. La exposición del $V$ Centenario, cat. exp., 31 de mayo - 11 de septiembre de 2016, Museo Nacional del Prado, Madrid. Madrid: Museo Nacional del Prado, 2016, 396 págs.

conjunto de elementos en que se funde lo animal con lo objetual debido al citado artista holandés (Museo Lázaro Galdiano, 2 de junio - 11 de septiembre de 2016). Como sabemos, El Bosco es uno de los artistas que ha despertado más interés entre los contemporáneos, desde los pintores hasta los diseñadores de moda. 